\title{
Chronic Adolescent Exposure to Delta-9-Tetrahydrocannabinol in COMT Mutant Mice: Impact on Indices of Dopaminergic, Endocannabinoid and GABAergic Pathways
}

\author{
Áine T Behan",', Magdalena Hryniewiecka', Colm MP O'Tuathaigh ${ }^{2,6}$, Anthony Kinsella ${ }^{2}$, Mary Cannon', \\ Maria Karayiorgou ${ }^{3}$, Joseph A Gogos ${ }^{4,5}$, John L Waddington ${ }^{2}$ and David R Cotter' \\ 'Department of Psychiatry, Royal College of Surgeons in Ireland, Dublin, Ireland; ${ }^{2}$ Molecular and Cellular Therapeutics, Royal College of Surgeons \\ in Ireland, Dublin, Ireland; ${ }^{3}$ Department of Psychiatry and Genetics \& Development, Columbia University, NY, USA; ${ }^{4}$ Department of Physiology \\ and Cellular Biophysics, Columbia University, NY, USA; ${ }^{5}$ Department of Neuroscience, Columbia University, NY, USA
}

\begin{abstract}
Cannabis use confers a two-fold increase in risk for psychosis, with adolescent use conferring an even greater risk. A high-low activity polymorphism in catechol-O-methyltransferase (COMT), a gene encoding the COMT enzyme involved in dopamine clearance in the brain, may interact with adolescent cannabis exposure to increase risk for schizophrenia. The impact of such an interaction on central neurotransmitter pathways implicated in schizophrenia is unknown. Male mice with knockout of the COMT gene were treated chronically with delta-9-tetrahydrocannabinol (THC) during adolescence (postnatal day 32-52). We measured the size and density of GABAergic cells and the protein expression of cannabinoid receptor I (CBIR) in the prefrontal cortex (PFC) and hippocampus (HPC) in knockout mice relative to heterozygous mutants and wild-type controls. Size and density of dopaminergic neurons was also assessed in the ventral tegmental area (VTA) across the genotypes. COMT genotype $\times$ THC treatment interactions were observed for: ( I) dopaminergic cell size in the VTA, (2) CBIR protein expression in the HPC, and (3) parvalbumin (PV) cell size in the PFC. No effects of adolescent THC treatment were observed for PV and dopaminergic cell density across the COMT genotypes. COMT genotype modulates the effects of chronic THC administration during adolescence on indices of neurotransmitter function in the brain. These findings illuminate how COMT deletion and adolescent cannabis use can interact to modulate the function of neurotransmitters systems implicated in schizophrenia.

Neuropsychopharmacology (2012) 37, I773-1783; doi:I0.I038/npp.2012.24; published online 2I March 2012
\end{abstract}

Keywords: delta-9-tetrahydrocannabinol; COMT; dopamine; GABA; gene $\times$ environment interaction; animal models

\section{INTRODUCTION}

The traditional hypothesis, widely held for several decades, is that increased dopaminergic function underlies the pathology of schizophrenia (Carlsson, 1978). More recently, the dopamine hypothesis of schizophrenia has been revised, with excess mesolimbic dopamine being secondary to lower dopamine levels in the prefrontal cortex (PFC) (Davis et al, 1991). In this context, the catechol-O-methyltransferase (COMT) gene on chromosome 22q11, a region implicated in schizophrenia, is functionally significant. It encodes the

*Correspondence/Current address: Dr ÁT Behan, Department of Physiology, Royal College of Surgeons in Ireland, 123 St Stephens Green, Dublin 2, Ireland. Tel: + 353 | 402 8579, Fax: + 353 | 402 2447, E-mail: abehan@rcsi.ie

${ }^{6}$ Current address: School of Medicine, University College Cork, Cork, Ireland.

Received 9 September 2011; revised 30 January 2012; accepted 6 February 2012
COMT enzyme responsible for the degradation of dopamine, particularly in the PFC. Furthermore, a valine to methionine substitution (valine substitution for methionine at the 158/108 locus Val158Met) within COMT was shown to reduce enzymatic activity of COMT, and thus lead to a slower breakdown of dopamine (Chen et al, 2004; Lachman et al, 1996). Reports have shown that a functional polymorphism in the COMT gene can moderate the association between cannabis use and psychosis (Caspi et al, 2005; Harrison and Weinberger, 2005; Tunbridge et al, 2006; van Os et al, 2010), but not all studies support such associations (Zammit et al, 2011). One particular study (Caspi et al, 2005) demonstrated that psychosis was most likely in those who used cannabis during adolescence and were homozygous for the COMT Val allele with the Met allele generating a four-fold reduction in enzymatic activity.

Mutant mice with deletion of the COMT gene have further elucidated the role of COMT in terms of dopamine-related function (Babovic et al, 2007; Seamans and Yang, 2004) of 
PFC-mediated cognition (Babovic et al, 2007; Gogos et al, 1998) and of spatial working memory. Thus, they have proved valuable in demonstrating the complexities of the inverted U-shaped dose-response relationship between PFC-mediated function and cortical dopaminergic activity involving the COMT gene, whereby a narrow range of dopamine can benefit PFC function and either insufficient or excessive dopamine can impair cognitive function (Castner et al, 2000; Goldman-Rakic et al, 2000; Seamans and Yang, 2004; Tunbridge et al, 2006). Moreover, a companion study by the authors have shown that the effects of chronic adolescent exposure to delta-9-tetrahydrocannabinol (THC) on behaviors related to psychosis and memory are modified in COMT mutant mice (O'Tuathaigh et al, 2010). No complementary analysis on neuronal structure has been performed in COMT mutant mice. Although it is known that single polymorphisms involve smaller effects on enzyme activity in humans, the COMT mutant mice provide an adequate model to further explore the modulatory role of COMT following adolescent cannabis use.

Cannabis use alone is not necessary or sufficient to cause the development of schizophrenia, which suggests that the association may be because of a genetic vulnerability to the effects of cannabis. In support of this, patients with schizophrenia or with an established vulnerability to psychosis are much more sensitive to the effects of cannabis than control subjects (D'Souza et al, 2005; Henquet et al, 2005; Stefanis et al, 2004; van Os et al, 2002; Verdoux et al, 2003). Nonetheless, consumption of cannabis is a risk factor for developing schizophrenia (Arseneault et al, 2004; Henquet et al, 2005; Moore et al, 2007), and the risk of developing psychotic symptoms is highest when cannabis is consumed during adolescence (Arseneault et al, 2002; Caspi et al, 2005; Konings et al, 2008; McGrath et al, 2010; Moore et al, 2007), possibly because the brain is still developing (Ehrenreich et al, 1999; Pistis et al, 2004; Pope et al, 2003; Schneider and Koch, 2003). Cannabinoid receptors mature slowly, reaching maximal levels during adolescence that possibly reduce later in life due to post-adolescent pruning, in a similar manner to that described for dopamine receptors (Belue et al, 1995; McLaughlin et al, 1994; Seeman, 1999). Studies have shown that heavy cannabis use, especially during adolescence, could contribute to additional changes in global brain structures (Arnone et al, 2008; Matochik et al, 2005; Welch et al, 2011; Wilson and Cadet, 2009; Yucel et al, 2008). However, the effect of cannabis use during adolescence on specific cell populations and their structure, particularly those implicated in schizophrenia, is less well understood.

THC, the main psychoactive ingredient of cannabis, is known to mediate its effect by binding to the cannabinoid receptor 1 (CB1R) (Pertwee, 2005); this is the main cannabinoid receptor in the brain, being expressed predominantly in the hippocampus (HPC), PFC, cerebellum, and basal ganglia (Freund et al, 2003). Endocannabinoids, the endogenous ligands of CB1R, are released by post-synaptic neurons to activate $\mathrm{CB} 1 \mathrm{R}$ on neighboring presynaptic neurons, which can in turn inhibit presynaptic neurotransmitter release of $\gamma$-aminobutyric acid (GABA) and glutamate, as well as modulating the dopamine system (Chevaleyre et al, 2006). It is also thought that dopaminergic midbrain neurons are modulated by endocannabinoid cortical neurons (Chevaleyre et al, 2006). Thus, the major neuronal populations modulated by cannabinoids are also ones implicated in schizophrenia (Laviolette and Grace, 2006; Lisman et al, 2008). How adolescent cannabis use and COMT genotype interact to modulate such structural changes, particularly in neuronal populations implicated in schizophrenia, is not yet understood.

Examination of morphological parameters such as neuronal cell size, cell density, and protein expression can provide complementary information on a neurons capacity to function (Behan et al, 2009; Cotter et al, 2002a, b). Recent reports have demonstrated deficits in GABAergic neuronal size and density (Cotter et al, 2002a) to be an indicator of pathophysiological deficits in schizophrenia and to be in line with functional assessments of the same neuronal populations (Hashimoto et al, 2003; Volk et al, 2001). In this study, we aimed to elucidate the impact of chronic THC treatment during adolescence on morphological indices of dopaminergic, cannabinoid, and GABAergic function in the brain and how they might be modified in COMT mutant mice.

\section{MATERIALS AND METHODS}

\section{Animals}

Mice containing the mutated COMT allele were generated at Rockefeller University, New York, NY, USA, and backcrossed to C57BL6 mice for 10 generations (Gogos et al, 1998); breeding and genotyping at the Royal College of Surgeons in Ireland were as described previously (Babovic et al, 2007). After weaning on postnatal day (PND) 21, pups from litters of the same generation were housed in groups of three to five per cage and maintained at $21 \pm 1^{\circ} \mathrm{C}$ on a $12-\mathrm{h}$ light/dark cycle (07:00 hours on; 19:00 hours off), with ad libitum access to food and water. Males of wild type (WT), COMT heterozygous (HET) and COMT knockout (KO) genotypes, 6-7 mice per treatment and genotype, were treated with THC $8.0 \mathrm{mg} / \mathrm{kg}$ subcutaneously or vehicle over 20 consecutive days (McKinney et al, 2008) from PND 32-52, a period corresponding to adolescence in mice (Vazdarjanova et al, 2011). These studies were approved by the Research Ethics Committee of the Royal College of Surgeons in Ireland. They were conducted under license from the Department of Health and Children, in accordance with Irish legislation and the European Communities Council Directive 86/609/EEC for the care and use of experimental animals, and from the Environmental Protection Agency in relation to the contained use of genetically modified organisms. All efforts were made to minimize the number of animals used and their suffering.

\section{Drugs}

Delta-9-tetrahydrocannabinol (Sigma Aldrich, St Louis, MO, USA) was dissolved in saline: cremaphor: ethanol (18:1:1); vehicle controls received identical injections of the final saline: cremaphor: ethanol solution.

\section{Immunofluorescent Staining}

Animals were killed at PND 150-160 by cervical dislocation. Whole brains were removed and post-fixed in $4 \%$ 
paraformaldehyde $(24 \mathrm{~h})$, cryoprotected in daily steps of $24 \mathrm{~h}$ in 10,20 , and $30 \%$ sucrose solution, and frozen in isopentane cooled on dry ice.

Serial coronal sections $(20 \mu \mathrm{m})$ were collected at the PFC, (Bregma $1.54-2.34 \mathrm{~mm}$ ), the HPC, (Bregma -1.34 to $-3.52 \mathrm{~mm}$ ), and the ventral tegmental area (VTA, Bregma -3.08 to $-3.88 \mathrm{~mm}$ ). Briefly, sections were incubated with primary antibodies against (1) monoclonal tyrosine hydroxylase (TH), a marker of dopaminergic neurons (1:500, Millipore, Cork Ireland) (2) monoclonal cannabinoid 1 receptor (CB1R, 1:2000, a kind gift from Dr Maurice Elphick), and (3) polyclonal parvalbumin (PV), a marker of a subset of GABAergic neurons $(1: 1000$, Abcam, Cambridge, UK), diluted in $5 \% \mathrm{NGS} / 1 \times \mathrm{PBS}-\mathrm{T}$. $\mathrm{PV}$ and $\mathrm{TH}$ antibodies were revealed by fluorescence using the respective conjugated Alexa Fluor 488 secondary antibody ( $1: 2000$ in 5\% NGS/PBS-T) and cover slipped using DAKO fluorescent mounting medium. CB1R antibody was visualized using the tyramide signal amplification kit (Perkin Elmer, Dublin, Ireland). All sections from each experimental group were immunostained in one single run under identical conditions with each run. A negative control, containing adjacent sections incubated in secondary antibody alone, that is, with the omission of the respective primary antibody, was included in every run. All morphometric measures were made by an observer blind to genotype and treatment.

\section{Quantitative Analysis of CB1R, PV, and TH Immunoreactivity}

All analyses were carried out on a Leica DM2500 microscope (Leica Microsystems, Ireland), a cooled monochrome 12-bit camera QI-IMAGING CAMERA Fast 1394 (Media Cybernetics, UK) and a Prior $\times 100 x, y$-motorized stage and stage controller (Media Cybernetics, UK) attached to a Heidenhain $z$ axis depth gauge (Heidenhain, Germany). Cross-sectional areas of VTA, PFC, and HPC were captured at $\times 20$ magnification and tiled using standardized exposure conditions. Boundaries of the VTA were defined by examining the size and shape of TH-IR neuronal groups and juxtaposition of other landmarks through reference to adjacent Nissl-stained VTA sections and a standard mouse atlas (Paxinos, 2008). The VTA was distinguished by the TH immunoreactive region bordered medially by the interpeduncular nucleus (IPN), laterally and ventrally by the substantia nigra pars compacta $(\mathrm{SNpc})$ and medial lemniscus (ML), and dorsally by the parabrachial pigmented nucleus. Representative $\mathrm{TH}$-immunoreactive sections of the VTA at $-3.00 \mathrm{~mm},-3.30 \mathrm{~mm}$, and $-3.60 \mathrm{~mm}$ with respect to Bregma are shown in Figure 1a. The location of PFC and HPC was defined using standard cytoarchitecture and subcortical landmarks as delineated in the Paxinos and Watson mouse brain atlas (Paxinos, 2008). Additionally, adjacent sections were stained with cresyl violet as described previously (Behan et al, 2010) and superimposed onto immunofluorescent images to accurately delineate PFC as well as the hippocampal formation, which included CA1, CA2/3, CA4, dentate gyrus, and subiculum.

Density and cell somal size of $\mathrm{PV}^{+}$neurons (Figure $1 \mathrm{~b}$ ) and $\mathrm{TH}^{+}$immunoreactive neurons (Figure 1d) were determined using morphometric methods, as outlined previously
(Cotter et al, 2002a). Areal fluorescent intensity of CB1R staining was also measured (Figure 1c). Density (cells $/ \mathrm{mm}^{2}$ ), two-dimensional cell somal size $\left(\mu \mathrm{m}^{2}\right)$, and fluorescent intensity (mean fluorescent intensity/ $/ \mathrm{m}^{2}$ ) were measured using Stereology-Pro 2.5 image analysis software (Kinetic Imaging, Liverpool, UK). From each animal, four crosssectional areas of the PFC, six cross-sectional areas of the HPC, and four cross-sectional areas of the VTA were analyzed for the respective $\mathrm{PV}^{+}, \mathrm{CB}_{1 \mathrm{R}}{ }^{+}$, and $\mathrm{TH}^{+}$morphometric assessments (Figures $1 \mathrm{~b}-\mathrm{d}$ ). The volume of the entire VTA (Figure 1a) was also estimated using stereological tools by the Cavalieri principle and the point-counting method (Behan et al, 2010; Gundersen et al, 1988). The coefficient of error for all morphometric measurements was $<5 \%$.

\section{Statistical Analysis}

All morphological measurements were analyzed using analysis of variance (ANOVA) with post-hoc comparisons by Fisher's test and corrected for multiple comparisons using Bonferroni correction as outlined previously (Babovic et al, 2007; O'Tuathaigh et al, 2007). For these measurements, we hypothesized a priori that the effects of chronic THC treatment during adolescence on dopaminergic, cannabinoid, and GABAergic neuronal populations in PFC, HPC, and VTA, respectively, were modified by COMT genotype. All statistical analyses were carried out using the SPSS software package (Version 14, SPSS, Chicago, IL, USA).

\section{RESULTS}

See Table 1 for a summary of morphological and densitometric assessments carried out for this study.

\section{TH Cell Counts in VTA}

A genotype $\times$ THC treatment interaction for $\mathrm{TH}^{+}$neuronal cell somal size in VTA $\left(\mathrm{F}_{2,25}=8.12 ; p=0.002\right)$ reflected an action of THC to reduce $\mathrm{TH}^{+}$neuronal cell somal size in COMT KO $\left(94.43 \pm 7.86 \mu \mathrm{m}^{2}\right)$ but not in WT $(111.20 \pm$ $\left.12.90 \mu \mathrm{m}^{2}\right)$ or COMT HET $\left(112.26 \pm 14.46 \mu \mathrm{m}^{2}\right)$ (Figure $2 \mathrm{a}$ ).

An effect of THC treatment on $\mathrm{TH}^{+}$cell density was observed in VTA $\left(\mathrm{F}_{1,25}=10.44 ; p=0.003\right)$, whereby THC reduced $\mathrm{TH}^{+}$cell density in a manner that did not differ between the genotypes (Figure $2 \mathrm{~b}$ ).

No effect of THC treatment on VTA volume was observed (Figure 2c).

\section{CB1R Intensity in the PFC and HPC}

An effect of genotype on CB1R intensity was observed in the PFC $\left(\mathrm{F}_{5,25}=8.07 ; p=0.01\right)$, whereby COMT HET mice $\left(63.54 \pm 5.90\right.$ intensity/ $\left.\mu \mathrm{m}^{2}\right)$ and COMT KO mice $(64.85 \pm$ 1.39 intensity/ $\mu \mathrm{m}^{2}$ ) expressed a higher CB1R intensity than WT $\left(60.17 \pm 5.14\right.$ intensity $\left./ \mu \mathrm{m}^{2}\right)$ (Figure 3a). Conversely, an effect of genotype on CB1R intensity was observed in HPC $\left(\mathrm{F}_{5,25}=4.75 ; p=0.015\right)$ whereby COMT KO mice $(33.76 \pm$ 3.10 intensity/ $/ \mathrm{m}^{2}$ ) expressed a lower CB1R intensity than WT $\left(37.27 \pm 3.30\right.$ intensity/ $/ \mathrm{m}^{2}$ ) (Figure $3 \mathrm{~b}$ ). No effects of THC on CB1R intensity were observed in PFC or HPC. 

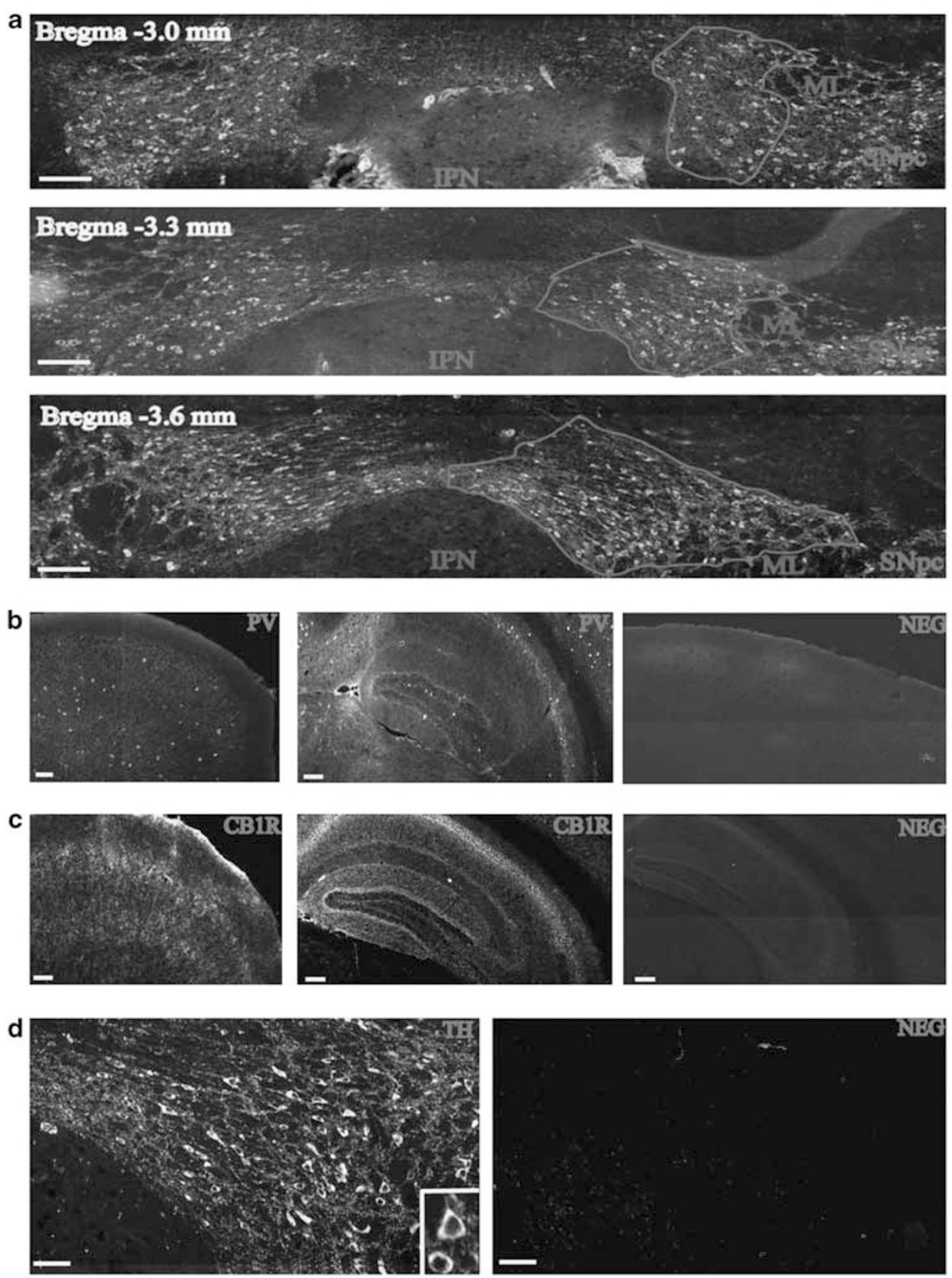

Figure I Delineation of ventral tegmental area (VTA) and representative immunofluorescent staining of PV, cannabinoid receptor I (CBIR), and TH in mouse brain. (a) Delineation of VTA using TH immunofluorescence at Bregma level $-3.0 \mathrm{~mm},-3.3 \mathrm{~mm}$, and $-3.6 \mathrm{~mm}$. VTA boundary landmarks are the interpeduncular nucleus (IPN) at the ventromedial border, the medial lemnicsus (ML), and the substantia nigra pars compacta (SNpc) at its most lateral and ventrolateral border; scale bar, $200 \mu \mathrm{m}$. (b) PV immunoreactivity in prefrontal cortex (PFC) (left), hippocampus (HPC) (centre), and negative control (NEG) in HPC (right); scale bar, $200 \mu \mathrm{m}$. (c) CBIR staining in PFC (left), HPC (centre), and CBIR-negative control in PFC (right); scale bar, $200 \mu \mathrm{m}$. (d) TH immunoreactivity in VTA (left, and inset showing TH-positive cell soma of neuron) and TH-negative control in VTA (right); scale bar, I00 $\mu$ m.

\section{PV Cell Somal Size and Density in PFC and HPC}

An effect of genotype on PV cell size was observed in the PFC $\left(\mathrm{F}_{2,25}=6.36 ; p=0.006\right)$, whereby $\mathrm{PV}$ cells were smaller in COMT HET $\left(140.67 \pm 12.07 \mu \mathrm{m}^{2}\right)$ than in COMT KO $\left(169.32 \pm 11.66 \mu \mathrm{m}^{2}\right)$, or WT $\left(146.42 \pm 7.89 \mu \mathrm{m}^{2}\right)$ (Figure 3c). A genotype $\times$ THC treatment interaction for PV cell somal size in PFC $\left(\mathrm{F}_{2,25}=7.04 ; p=0.004\right)$ reflected an action of THC to increase PV cell somal size in WT, to be without effect in HET and to decrease PV cell somal size in COMT KO (Figure 3c). An effect of genotype on PV cell size was observed in $\mathrm{HPC}\left(\mathrm{F}_{2}, 25=8.021 ; p=0.002\right)$, whereby PV cells were smaller in COMT KO $\left(165.44 \pm 3.58 \mu \mathrm{m}^{2}\right)$ and particularly in COMT HET $\left(154.83 \pm 11.91 \mu \mathrm{m}^{2}\right)$ than in WT $\left(171.85 \pm 8.01 \mu \mathrm{m}^{2}\right)$ (Figure $3 \mathrm{~d}$ ). There were no effects of genotype, THC treatment or gene $\times$ THC treatment interactions for PV cell density in PFC or HPC (Figures 3e and $\mathrm{f}$ ). 
It was noteworthy that $\mathrm{CB} 1 \mathrm{R}$ intensity inversely correlated strongly with PV cell size in PFC $(r=-0.55, p<0.001)$ and HPC $(r=-0.46, p<0.01)$.

\section{DISCUSSION}

In this study, the effects on morphological indices of GABAergic, dopaminergic, and cannabinoid function were assessed in COMT mutant mice, following chronic THC treatment during adolescence. To our knowledge, this is the first study to assess the combined effects of COMT activity and adolescent THC administration on cannabinoid-modulated neuronal populations implicated in schizophrenia. As human polymorphisms elicit smaller effects on enzyme activity, our COMT mutant mice do not serve to replicate such findings here but to illuminate the modulatory role of COMT on other neuronal populations in the brain, following chronic THC administration. On the basis of previous findings, indicating a sexually dimorphic effect of COMT function on psychiatric phenotypes to be evident primarily in males (Gogos et al, 1998; O'Tuathaigh et al, 2010), we assessed male COMT mutant mice. On the basis of our behavioral studies on COMT mutant mice, indicating COMT genotype to influence the effects of adolescent THC administration on schizophrenia-related behavioral phenotypes (O'Tuathaigh et al, 2010), the same treatment regimen was employed in the present study. We examined morphological parameters such as neuronal cell size, cell density, and protein expression to obtain morphological correlates on the functional capacity of specific neuronal populations (Behan et al, 2009; Cotter et al, 2002a, b). Given that the COMT mutant model was based on a higher COMT activity being a risk factor for schizophrenia, our results show that COMT deletion is associated with: (1) release of an effect of adolescent THC treatment in VTA that reduced dopaminergic cell size, (2) increased CBR1 intensity in PFC, reduced CBR1 intensity in HPC, and a shift in effect of adolescent THC treatment in HPC and PFC from reduction to increase in CBR1 intensity, and (3) increased GABAergic cell size in PFC and HPC, and a shift in effect of adolescent THC treatment in PFC and HPC from increase to decrease in GABAergic cell size. Adolescent THC treatment also reduced dopaminergic cell density. COMT KO mice demonstrated the prominent structural neuronal deficits in this study.

\section{COMT Modulation of Adolescent THC Effects on Neurotransmitter Systems}

Dopaminergic neurons. A functional polymorphism in the COMT gene moderates the risk to develop psychosis, following adolescent cannabis use with individuals homozygous for the COMT Val allele possessing a higher risk for psychosis, following adolescent cannabis use (Caspi et al, 2005; Henquet et al, 2006). This is attributable to increased COMT activity associated with the COMT Val allele in the PFC leading to a reduction in PFC dopamine neurotransmission and increased mesolimbic dopamine signaling; the converse would be hypothesized for the COMT Met allele (Akil et al, 2003; Bilder et al, 2004). THC challenge studies in humans have demonstrated significant increases in striatal dopamine release after acute administration of 
a

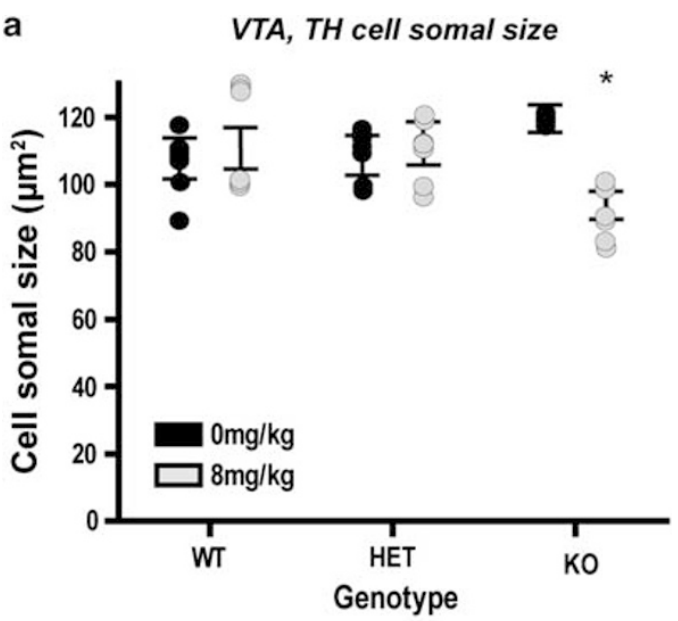

b

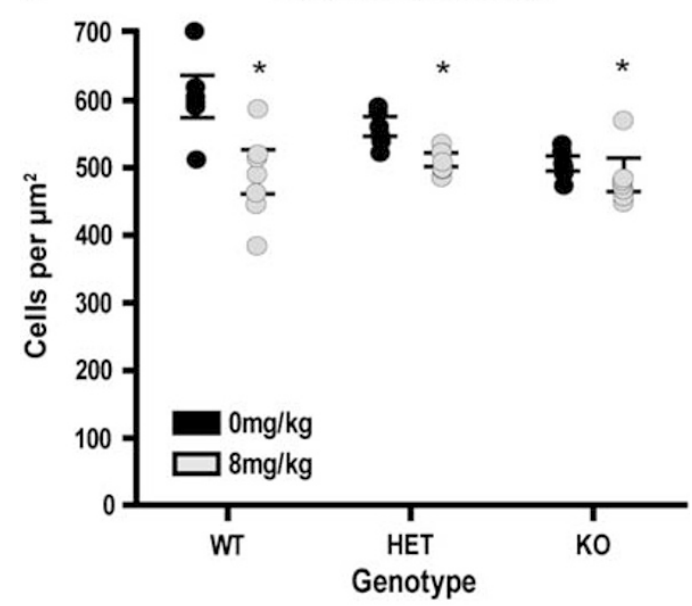

C

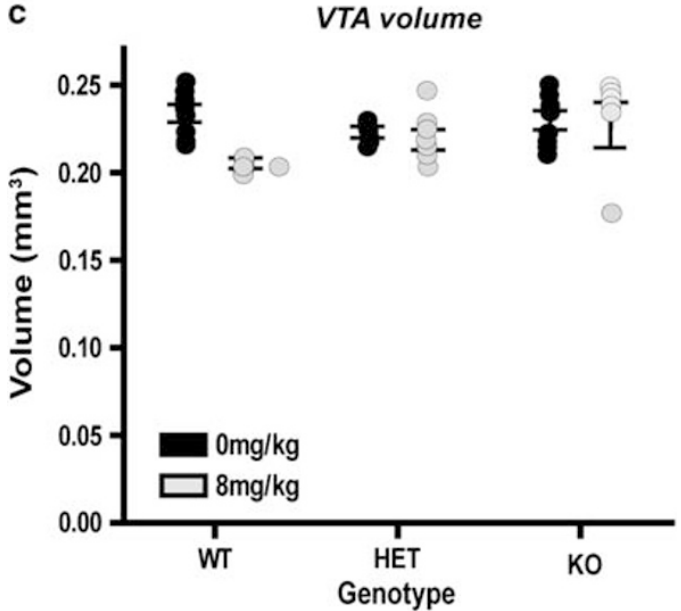

Figure 2 Somal size (a), cell density (b), and ventral tegmental area (VTA) volume (c) for TH-positive cells in VTA during adulthood, following adolescent treatment with $8.0 \mathrm{mg} / \mathrm{kg}$ delta-9-tetrahydrocannabinol (THC) or vehicle (0). Data are means $\pm \mathrm{SEM}$; ${ }^{*} p<0.015$.

inhaled THC (Bossong et al, 2009); however, such findings could not be replicated in a larger cohort (Stokes et al, 2010, 2011). In animal studies, THC increased dopaminergic neuronal firing and dopamine release in the striatum and
PFC (Cheer et al, 2004; Chen et al, 1990; French, 1997; French et al, 1997; Pistis et al, 2002; Tanda et al, 1997). PFC is the dominant COMT site in the brain for modulating dopamine metabolism whereas the dopamine transporter (DAT), found at a much higher density in the striatum, is mainly responsible for regulating striatal dopamine levels (Scatton et al, 1985; Yavich et al, 2007). Male COMT KO mice used in this study have previously demonstrated higher basal levels of dopamine release, dopamine levels, and its metabolites in PFC of COMT KO mice (Gogos et al, 1998; O'Tuathaigh et al, 2011). Given the evidence of COMTs regulatory role in the PFC (and not the striatum) (Scatton et al, 1985; Yavich et al, 2007), we would speculate that changes to COMT activity in PFC are having a knockon effect on the activity and output of dopaminergic cortical neurons. It is possible that our observations of smaller tyrosine hydroxylase-labeled dopaminergic neurons in VTA in COMT KO mice following THC treatment occurs in response to altered input from cortical dopaminergic neurons (Akil et al, 2003). This further highlights a role for prefrontal COMT levels in the regulation of and communication between cortical and subcortical dopaminergic neuronal populations.

The aforementioned pattern of midbrain dopaminergic signaling is similar to that proposed to be present among subjects carrying the COMT Met allele (Akil et al, 2003; Bilder et al, 2004). We propose that lower cortical COMT activity may lead, through increased cortical dopaminergic activity, to reduced midbrain dopaminergic function, and hence, neuronal size. No changes in the structure of VTA dopaminergic neurons were observed in male COMT WT and HET mice. Our findings indicate that COMT genotype and adolescent THC exposure together can modulate dopaminergic neuronal structure in the mesolimbic system. Changes in dopaminergic neuron structure may reflect a cellular pathology that accompanies changes in dopaminergic activity as have been observed in other neuronal populations implicated in schizophrenia (Cotter et al, 2002a). Relating such structure-function findings are relevant to our understanding of the pathophysiology of schizophrenia, as excessive activity of dopaminergic neurons in VTA has also been proposed to have a role in the emergence of psychotic symptoms in schizophrenia (D'Souza et al, 2005; Henquet et al, 2005; Stefanis et al, 2004; van Os et al, 2002; Verdoux et al, 2003).

Cannabinoid 1 receptor and the endocannabinoid pathway. Dysfunction in PFC is strongly implicated in schizophrenia (Lafourcade et al, 2007) and within it, CB1R expression is reported to be reduced (Eggan et al, 2010). Our observation of reduction in CB1R expression in PFC and HPC of WT mice following adolescent THC treatment is in accordance with previous $\mathrm{CB} 1 \mathrm{R}$ binding and protein expression studies in animals, following THC treatment (Romero et al, 1997, 1998). Furthermore, this finding is in line with what we would have predicted from our model based on a higher COMT activity and THC administration being a risk factor for schizophrenia (Caspi et al, 2005). Conversely, we observed a shift in this pattern, from reduction to increase in $\mathrm{CB} 1 \mathrm{R}$ expression in $\mathrm{PFC}$ and $\mathrm{HPC}$, in COMT KO mice following adolescent THC treatment. This affirms structural significance and interdependence of 

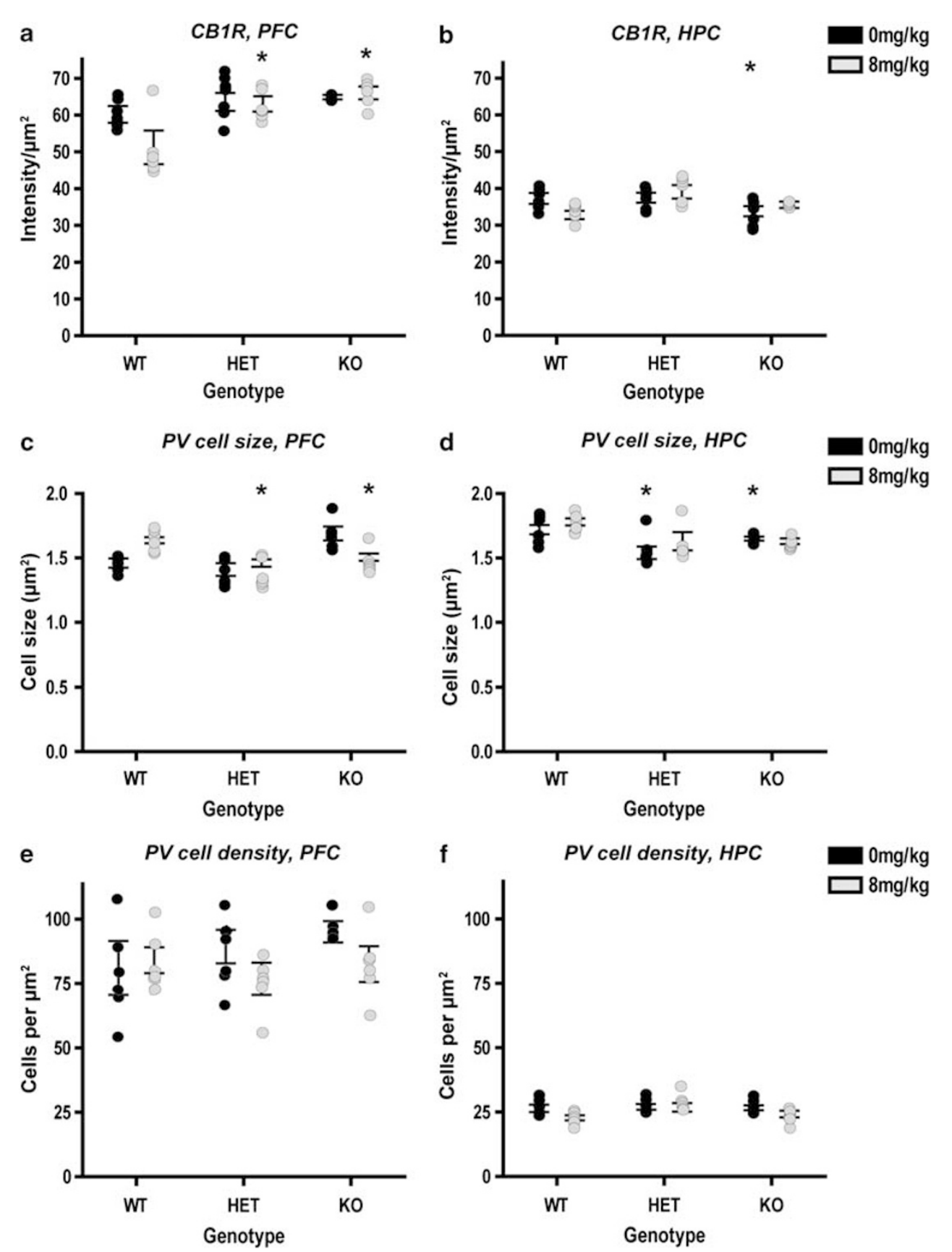

Figure 3 Cannabinoid receptor I (CBIR) intensity in prefrontal cortex (PFC) (a) and hippocampus (HPC) (b), PV cell size in PFC (c) and HPC (d), and PV cell density in PFC (e) and HPC (f) during adulthood, following adolescent treatment with $8.0 \mathrm{mg} / \mathrm{kg}$ delta-9-tetrahydrocannabinol (THC) or vehicle (0). Data are means $\pm \mathrm{SEM} ; *$ $P<0.015$.

COMT activity and the endocannabinoid system (Chevaleyre et al, 2006; Fride, 2005), and may be relevant to the known association of cannabis use with increased levels of psychotic symptoms (D'Souza et al, 2005; Henquet et al, 2005; Stefanis et al, 2004; van Os et al, 2002; Verdoux et al, 2003). It also emphasizes further the developmental period of adolescence and its vulnerability to subsequent effects of cannabis.

THC is known to affect endocannabinoid neurotransmission with components of this endocannabinoid pathway shown to be involved in regulating dopaminergic neurotransmission, particularly in the striatum (Cheer et al, 2004; Chen et al, 1990; Tanda et al, 1997). Furthermore, THC, which acts through activation of $\mathrm{CB} 1$ receptors, is known to increase firing of dopaminergic neurons in the midbrain (Diana et al, 1998; French et al, 1997) and these same midbrain dopamine neurons regulate excitatory and inhibitory inputs by retrograde endocannabinoid signaling (Chevaleyre et al, 2006; Lupica and Riegel, 2005; Matyas et al, 2008). The effects of cannabinoids such as THC on dopaminergic mesolimbic neurotransmission are usually indirect (FernandezRuiz et al, 2010); it is thought that CB1R at GABAergic and 
glutamatergic synapses facilitate such indirect actions (Herkenham et al, 1990; Mailleux and Vanderhaeghen, 1992; Tsou et al, 1998). Therefore, our findings of smaller VTA dopaminergic neurons following THC treatment may occur in response to higher cortical CB1R levels in COMT KO mice (Akil et al, 2003). Our finding that adolescent THC treatment and COMT genotype interact to modulate VTA dopaminergic neuron size in adult mice may reflect an effect of endocannabinoid regulation on mesolimbic dopaminergic neuron populations following adolescent THC exposure, a critical period of brain development (Ehrenreich et al, 1999; Pope et al, 2003). On this basis, we propose that dysregulation of dopaminergic neurons in VTA in schizophrenia (Akil et al, 2003; Bilder et al, 2004) may be exacerbated by adolescent THC-induced, CB1R-mediated, long-term impairment in mesolimbic dopaminergic neuron structure and, hence, signaling.

GABAergic neurons. Dysfunction in GABAergic systems is evident in schizophrenia, with GABA synthesis and reuptake reduced in PFC and HPC (Heckers et al, 2002; Konradi et al, 2011; Volk et al, 2001). Furthermore, cell density of GABAergic neurons, in particular the number of $\mathrm{PV}$-positive neurons, is decreased in PFC and HPC of patients with schizophrenia (Benes et al, 1991, 1998; Hashimoto et al, 2003; Konradi et al, 2011). Given these studies and based on a higher COMT activity being a risk factor for schizophrenia, one would have predicted deficits in cortical GABAergic neuronal populations in COMT WT mice, where the PFC would be hypodopaminergic and GABAergic inhibition would not be strong. Instead, GABAergic deficits were observed by a reduction in cell size in COMT KO mice and not COMT WT mice. The conventional inverted-U shape curve of dopaminergic modulation of the PFC activity may provide some understanding given that deficient or excessive dopamine activity exert disruptive effects on normal neuronal structure (Seamans and Yang, 2004). As dopamine is capable of having an inhibitory effect on cortical GABA neurons (Retaux et al, 1991), it is possible that an excessive release of prefrontal dopamine in COMT KO mice could lead to impairments in normal GABAergic neuronal structure. Conversely, GABAergic neurons in VTA are anatomically positioned to influence the activity of the dopamine system in the mesolimbic pathway (Laviolette and van der Kooy, 2001); so, changes in GABAergic neurons could be responsible for altering the activity and structure of neighboring dopaminergic neurons.

It is not yet clear how reduction in the size of $\mathrm{PV}^{+}$ GABAergic neurons in COMT $\mathrm{KO}$ mice in response to adolescent THC treatment relates to the upregulation of cortical CB1R protein expression in COMT HET and KO mice, following adolescent THC exposure. However, given our findings of a significant inverse correlation between CB1R and PV cell size and that endocannabinoids are known to modify inhibition in GABAergic neurons (Lovinger, 2008), it is also possible that enhanced expression of cortical CB1R (by THC treatment) may alter the size of cortical GABAergic populations and, consequently, modify GABAergic signaling in COMT mutant mice. Our GABAergic findings in the COMT mutant mouse are interesting, given that most of the effects of the endocannabinoid system on dopaminergic neurotransmission are GABA- and/or glutamate-mediated (Herkenham et al, 1990; Mailleux and Vanderhaeghen, 1992; Tsou et al, 1998). Additionally, endocannabinoids such as THC are responsible for retrograde signaling of CB1R on GABAergic neurons and, through this mechanism, can prevent excess inhibition at GABAergic synapses (Lovinger, 2008). Upregulation of cortical CB1R protein expression in COMT HET and $\mathrm{KO}$ mice, following adolescent THC exposure, may thus mediate the reduction observed in midbrain dopaminergic neuronal cell size through CB1Rs cortical action on GABAergic neurons. How this occurs may have a functional origin arising from a dampened inhibition of GABAergic neurons brought, which, in turn, can be mediated by the increased expression observed in CB1R-enhanced endocannabinoid signaling (Lovinger, 2008).

There is certainly a higher order of complexity in how these systems interact that should be interpreted with caution. Nonetheless, the GABAergic changes observed in this gene $\times$ environmental mouse model and their relationship to schizophrenia indicate further the vulnerability to, and consequent dysregulation of, neurotransmitter systems by developmental insults such as THC treatment during adolescence.

\section{Summary}

These studies elaborate and suggest putative mechanisms underlying recent clinical findings that cannabis use during adolescence, and subsequent psychosis is influenced by the human COMT genotype (Caspi et al, 2005). The higher activity COMT Val allele has demonstrated in some, but not all, human studies to be associated with increased risk of schizophrenia following THC exposure during adolescence (Caspi et al, 2005; Zammit et al, 2011). It might have been predicted, based on a higher COMT activity being a risk factor for schizophrenia, that COMT KO mice exposed to adolescent THC would evidence fewer schizophrenia-related neuronal changes than WT mice, that is, relative hyperdopaminergia in mesolimbic systems (Akil et al, 2003), reduced density of cortical and hippocampal GABAergic neurons (Cotter et al, 2002a), and reduced CB1R expression (Eggan et al, 2010). However, the opposite was observed; COMT KO mice demonstrated the more prominent structural neuronal deficits. These findings may reflect complexities arising from the inverted U-shaped relationship between corticalmediated function and cortical dopaminergic activity in human/non-human primates vis-à-vis rodents, such that deficient or excessive dopamine activity could each exert disruptive effects on normal neuronal structure (O’Tuathaigh et al, 2010, 2011; Seamans and Yang, 2004; Tunbridge et al, 2006). Additionally, future comparative studies investigating these same paradigms in mice expressing variants of human COMT are required to rule out any probability of our COMT KO findings arising from developmental compensation in dopaminergic, CB1R, and GABAergic systems.

Our findings indicate disruptive effects of adolescent THC exposure on several neuronal populations, in a manner that can be modulated by COMT genotype. They demonstrate how genetic, developmental, and environmental factors can interact to modulate the cellular structure of neuronal 
populations implicated in schizophrenia such as the dopaminergic, endocannabinoid, and GABAergic systems.

\section{ACKNOWLEDGEMENTS}

This study was supported by Science Foundation Ireland (DC: 05/RFP/BMI0016; JLW: 07/IN.1/B960), and the Health Research Board (CO’T: PD/2007/20; MC: CSA/2004/1).

\section{DISCLOSURE}

The authors declare no conflict of interest.

\section{REFERENCES}

Akil M, Kolachana BS, Rothmond DA, Hyde TM, Weinberger DR, Kleinman JE (2003). Catechol-O-methyltransferase genotype and dopamine regulation in the human brain. J Neurosci 23: 20082013.

Arnone D, Barrick TR, Chengappa S, Mackay CE, Clark CA, AbouSaleh MT (2008). Corpus callosum damage in heavy marijuana use: preliminary evidence from diffusion tensor tractography and tract-based spatial statistics. Neuroimage 41: 1067-1074.

Arseneault L, Cannon M, Poulton R, Murray R, Caspi A, Moffitt TE (2002). Cannabis use in adolescence and risk for adult psychosis: longitudinal prospective study. BMJ 325: 1212-1213.

Arseneault L, Cannon M, Witton J, Murray RM (2004). Causal association between cannabis and psychosis: examination of the evidence. Br J Psychiatry 184: 110-117.

Babovic D, O'Tuathaigh CM, O'Sullivan GJ, Clifford JJ, Tighe O, Croke DT et al (2007). Exploratory and habituation phenotype of heterozygous and homozygous COMT knockout mice. Behav Brain Res 183: 236-239.

Behan AT, Byrne C, Dunn MJ, Cagney G, Cotter DR (2009). Proteomic analysis of membrane microdomain-associated proteins in the dorsolateral prefrontal cortex in schizophrenia and bipolar disorder reveals alterations in LAMP, STXBP1 and BASP1 protein expression. Mol Psychiatry 14: 601-613.

Behan AT, van den Hove DL, Mueller L, Jetten MJ, Steinbusch HW, Cotter DR et al (2010). Evidence of female-specific glial deficits in the hippocampus in a mouse model of prenatal stress. Eur Neuropsychopharmacol 21: 71-79.

Belue RC, Howlett AC, Westlake TM, Hutchings DE (1995). The ontogeny of cannabinoid receptors in the brain of postnatal and aging rats. Neurotoxicol Teratol 17: 25-30.

Benes FM, Kwok EW, Vincent SL, Todtenkopf MS (1998). A reduction of nonpyramidal cells in sector CA2 of schizophrenics and manic depressives. Biol Psychiatry 44: 88-97.

Benes FM, McSparren J, Bird ED, SanGiovanni JP, Vincent SL (1991). Deficits in small interneurons in prefrontal and cingulate cortices of schizophrenic and schizoaffective patients. Arch Gen Psychiatry 48: 996-1001.

Bilder RM, Volavka J, Lachman HM, Grace AA (2004). The catechol-O-methyltransferase polymorphism: relations to the tonic-phasic dopamine hypothesis and neuropsychiatric phenotypes. Neuropsychopharmacology 29: 1943-1961.

Bossong MG, van Berckel BN, Boellaard R, Zuurman L, Schuit RC, Windhorst $\mathrm{AD}$ et al (2009). Delta 9-tetrahydrocannabinol induces dopamine release in the human striatum. Neuropsychopharmacology 34: 759-766.

Carlsson A (1978). Does dopamine have a role in schizophrenia? Biol Psychiatry 13: 3-21.

Caspi A, Moffitt TE, Cannon M, McClay J, Murray R, Harrington $\mathrm{H}$ et al (2005). Moderation of the effect of adolescent-onset cannabis use on adult psychosis by a functional polymorphism in the catechol-O-methyltransferase gene: longitudinal evidence of a gene X environment interaction. Biol Psychiatry 57: 11171127.

Castner SA, Williams GV, Goldman-Rakic PS (2000). Reversal of antipsychotic-induced working memory deficits by short-term dopamine D1 receptor stimulation. Science 287: 2020-2022.

Cheer JF, Wassum KM, Heien ML, Phillips PE, Wightman RM (2004). Cannabinoids enhance subsecond dopamine release in the nucleus accumbens of awake rats. J Neurosci 24: 4393-4400.

Chen J, Lipska BK, Halim N, Ma QD, Matsumoto M, Melhem S et al (2004). Functional analysis of genetic variation in catechol-Omethyltransferase (COMT): effects on mRNA, protein, and enzyme activity in postmortem human brain. Am J Hum Genet 75: 807-821.

Chen JP, Paredes W, Li J, Smith D, Lowinson J, Gardner EL (1990). Delta 9-tetrahydrocannabinol produces naloxone-blockable enhancement of presynaptic basal dopamine efflux in nucleus accumbens of conscious, freely-moving rats as measured by intracerebral microdialysis. Psychopharmacology (Berl) 102: 156-162.

Chevaleyre V, Takahashi KA, Castillo PE (2006). Endocannabinoid-mediated synaptic plasticity in the CNS. Annu Rev Neurosci 29: 37-76.

Cotter D, Landau S, Beasley C, Stevenson R, Chana G, MacMillan L et al (2002a). The density and spatial distribution of GABAergic neurons, labelled using calcium binding proteins, in the anterior cingulate cortex in major depressive disorder, bipolar disorder, and schizophrenia. Biol Psychiatry 51: 377-386.

Cotter D, Mackay D, Chana G, Beasley C, Landau S, Everall IP (2002b). Reduced neuronal size and glial cell density in area 9 of the dorsolateral prefrontal cortex in subjects with major depressive disorder. Cereb Cortex 12: 386-394.

Davis KL, Kahn RS, Ko G, Davidson M (1991). Dopamine in schizophrenia: a review and reconceptualization. Am J Psychiatry 148: $1474-1486$.

Diana M, Melis M, Gessa GL (1998). Increase in meso-prefrontal dopaminergic activity after stimulation of CB1 receptors by cannabinoids. Eur J Neurosci 10: 2825-2830.

D’Souza DC, Abi-Saab WM, Madonick S, Forselius-Bielen K, Doersch A, Braley G et al (2005). Delta-9-tetrahydrocannabinol effects in schizophrenia: implications for cognition, psychosis, and addiction. Biol Psychiatry 57: 594-608.

Eggan SM, Stoyak SR, Verrico CD, Lewis DA (2010). Cannabinoid CB1 receptor immunoreactivity in the prefrontal cortex: comparison of schizophrenia and major depressive disorder. Neuropsychopharmacology 35: 2060-2071.

Ehrenreich H, Rinn T, Kunert HJ, Moeller MR, Poser W, Schilling $\mathrm{L}$ et al (1999). Specific attentional dysfunction in adults following early start of cannabis use. Psychopharmacology (Berl) 142: $295-301$.

Fernandez-Ruiz J, Hernandez M, Ramos JA (2010). Cannabinoiddopamine interaction in the pathophysiology and treatment of CNS disorders. CNS Neurosci Ther 16: e72-e91.

French ED (1997). delta9-Tetrahydrocannabinol excites rat VTA dopamine neurons through activation of cannabinoid CB1 but not opioid receptors. Neurosci Lett 226: 159-162.

French ED, Dillon K, Wu X (1997). Cannabinoids excite dopamine neurons in the ventral tegmentum and substantia nigra. Neuroreport 8: 649-652.

Freund TF, Katona I, Piomelli D (2003). Role of endogenous cannabinoids in synaptic signaling. Physiol Rev 83: 1017-1066.

Fride E (2005). Endocannabinoids in the central nervous system: from neuronal networks to behavior. Curr Drug Targets CNS Neurol Disord 4: 633-642.

Gogos JA, Morgan M, Luine V, Santha M, Ogawa S, Pfaff D et al (1998). Catechol-O-methyltransferase-deficient mice exhibit sexually dimorphic changes in catecholamine levels and behavior. Proc Natl Acad Sci USA 95: 9991-9996. 
Goldman-Rakic PS, Muly 3rd EC, Williams GV (2000). D(1) receptors in prefrontal cells and circuits. Brain Res Brain Res Rev 31: 295-301.

Gundersen HJ, Bagger P, Bendtsen TF, Evans SM, Korbo L, Marcussen N et al (1988). The new stereological tools: disector, fractionator, nucleator and point sampled intercepts and their use in pathological research and diagnosis. APMIS 96: 857-881.

Harrison PJ, Weinberger DR (2005). Schizophrenia genes, gene expression, and neuropathology: on the matter of their convergence. Mol Psychiatry 10: 40-68.

Hashimoto T, Volk DW, Eggan SM, Mirnics K, Pierri JN, Sun Z et al (2003). Gene expression deficits in a subclass of GABA neurons in the prefrontal cortex of subjects with schizophrenia. J Neurosci 23: 6315-6326.

Heckers S, Stone D, Walsh J, Shick J, Koul P, Benes FM (2002). Differential hippocampal expression of glutamic acid decarboxylase 65 and 67 messenger RNA in bipolar disorder and schizophrenia. Arch Gen Psychiatry 59: 521-529.

Henquet C, Krabbendam L, Spauwen J, Kaplan C, Lieb R, Wittchen HU et al (2005). Prospective cohort study of cannabis use, predisposition for psychosis, and psychotic symptoms in young people. BMJ 330: 11.

Henquet C, Rosa A, Krabbendam L, Papiol S, Fananas L, Drukker $M$ et al (2006). An experimental study of catechol-o-methyltransferase Val158Met moderation of delta-9-tetrahydrocannabinolinduced effects on psychosis and cognition. Neuropsychopharmacology 31: 2748-2757.

Herkenham M, Lynn AB, Little MD, Johnson MR, Melvin LS, de Costa BR et al (1990). Cannabinoid receptor localization in brain. Proc Natl Acad Sci USA 87: 1932-1936.

Konings M, Henquet C, Maharajh HD, Hutchinson G, Van Os J (2008). Early exposure to cannabis and risk for psychosis in young adolescents in Trinidad. Acta Psychiatr Scand 118: 209-213.

Konradi C, Yang CK, Zimmerman EI, Lohmann KM, Gresch P, Pantazopoulos $\mathrm{H}$ et al (2011). Hippocampal interneurons are abnormal in schizophrenia. Schizophr Res 131: 165-173.

Lachman HM, Papolos DF, Saito T, Yu YM, Szumlanski CL, Weinshilboum RM (1996). Human catechol-O-methyltransferase pharmacogenetics: description of a functional polymorphism and its potential application to neuropsychiatric disorders. Pharmacogenetics 6: 243-250.

Lafourcade M, Elezgarai I, Mato S, Bakiri Y, Grandes P, Manzoni OJ (2007). Molecular components and functions of the endocannabinoid system in mouse prefrontal cortex. PLoS One 2: e709.

Laviolette SR, Grace AA (2006). The roles of cannabinoid and dopamine receptor systems in neural emotional learning circuits: implications for schizophrenia and addiction. Cell Mol Life Sci 63: 1597-1613.

Laviolette SR, van der Kooy D (2001). GABA(A) receptors in the ventral tegmental area control bidirectional reward signalling between dopaminergic and non-dopaminergic neural motivational systems. Eur J Neurosci 13: 1009-1015.

Lisman JE, Coyle JT, Green RW, Javitt DC, Benes FM, Heckers S et al (2008). Circuit-based framework for understanding neurotransmitter and risk gene interactions in schizophrenia. Trends Neurosci 31: 234-242.

Lovinger DM (2008). Presynaptic modulation by endocannabinoids. Handb Exp Pharmacol 184: 435-477.

Lupica CR, Riegel AC (2005). Endocannabinoid release from midbrain dopamine neurons: a potential substrate for cannabinoid receptor antagonist treatment of addiction. Neuropharmacology 48: 1105-1116.

Mailleux P, Vanderhaeghen JJ (1992). Distribution of neuronal cannabinoid receptor in the adult rat brain: a comparative receptor binding radioautography and in situ hybridization histochemistry. Neuroscience 48: 655-668.
Matochik JA, Eldreth DA, Cadet JL, Bolla KI (2005). Altered brain tissue composition in heavy marijuana users. Drug Alcohol Depend 77: 23-30.

Matyas F, Urban GM, Watanabe M, Mackie K, Zimmer A, Freund TF et al (2008). Identification of the sites of 2-arachidonoylglycerol synthesis and action imply retrograde endocannabinoid signaling at both GABAergic and glutamatergic synapses in the ventral tegmental area. Neuropharmacology 54: 95-107.

McGrath J, Welham J, Scott J, Varghese D, Degenhardt L, Hayatbakhsh MR et al (2010). Association between cannabis use and psychosis-related outcomes using sibling pair analysis in a cohort of young adults. Arch Gen Psychiatry 67: 440-447.

McKinney DL, Cassidy MP, Collier LM, Martin BR, Wiley JL, Selley DE et al (2008). Dose-related differences in the regional pattern of cannabinoid receptor adaptation and in vivo tolerance development to delta9-tetrahydrocannabinol. J Pharmacol Exp Ther 324: 664-673.

McLaughlin CR, Martin BR, Compton DR, Abood ME (1994). Cannabinoid receptors in developing rats: detection of mRNA and receptor binding. Drug Alcohol Depend 36: 27-31.

Moore TH, Zammit S, Lingford-Hughes A, Barnes TR, Jones PB, Burke $M$ et al (2007). Cannabis use and risk of psychotic or affective mental health outcomes: a systematic review. Lancet 370: 319-328.

O’Tuathaigh CM, Babovic D, O’Meara G, Clifford JJ, Croke DT, Waddington JL (2007). Susceptibility genes for schizophrenia: characterisation of mutant mouse models at the level of phenotypic behaviour. Neurosci Biobehav Rev 31: 60-78.

O'Tuathaigh CM, Clarke G, Walsh J, Desbonnet L, Petit E, O'Leary C et al (2011). Genetic vs pharmacological inactivation of COMT influences cannabinoid-induced expression of schizophrenia-related phenotypes. Int J Neuropsychopharmacol; e-pub ahead of print 11 November 2011.

O’Tuathaigh CM, Hryniewiecka M, Behan Á, Tighe O, Coughlan C, Desbonnet L et al (2010). Chronic adolescent exposure to delta9-tetrahydrocannabinol in COMT mutant mice: impact on psychosis-related and other phenotypes. Neuropsychopharmacology 35: 2262-2273.

Paxinos G, Franklin KBJ (2008). The Mouse Brain in Stereotaxic Coordinates, Compact, Third Edition: The Coronal Plates and Diagrams, 3 edn. Academic Press: Allen Institute.

Pertwee RG (2005). Pharmacological actions of cannabinoids. Handb Exp Pharmacol 168: 1-51.

Pistis M, Ferraro L, Pira L, Flore G, Tanganelli S, Gessa GL et al (2002). Delta(9)-tetrahydrocannabinol decreases extracellular GABA and increases extracellular glutamate and dopamine levels in the rat prefrontal cortex: an in vivo microdialysis study. Brain Res 948: 155-158.

Pistis M, Perra S, Pillolla G, Melis M, Muntoni AL, Gessa GL (2004). Adolescent exposure to cannabinoids induces longlasting changes in the response to drugs of abuse of rat midbrain dopamine neurons. Biol Psychiatry 56: 86-94.

Pope Jr HG, Gruber AJ, Hudson JI, Cohane G, Huestis MA, Yurgelun-Todd D (2003). Early-onset cannabis use and cognitive deficits: what is the nature of the association? Drug Alcohol Depend 69: 303-310.

Retaux S, Besson MJ, Penit-Soria J (1991). Synergism between D1 and D2 dopamine receptors in the inhibition of the evoked release of [3H]GABA in the rat prefrontal cortex. Neuroscience 43: 323-329.

Romero J, Berrendero F, Manzanares J, Perez A, Corchero J, Fuentes JA et al (1998). Time-course of the cannabinoid receptor down-regulation in the adult rat brain caused by repeated exposure to delta9-tetrahydrocannabinol. Synapse 30: 298-308.

Romero J, Garcia-Palomero E, Castro JG, Garcia-Gil L, Ramos JA, Fernandez-Ruiz JJ (1997). Effects of chronic exposure to delta9tetrahydrocannabinol on cannabinoid receptor binding and mRNA levels in several rat brain regions. Brain Res Mol Brain Res 46: 100-108. 
Scatton B, Dubois A, Dubocovich ML, Zahniser NR, Fage D (1985). Quantitative autoradiography of $3 \mathrm{H}$-nomifensine binding sites in rat brain. Life Sci 36: 815-822.

Schneider M, Koch M (2003). Chronic pubertal, but not adult chronic cannabinoid treatment impairs sensorimotor gating, recognition memory, and the performance in a progressive ratio task in adult rats. Neuropsychopharmacology 28: 1760-1769.

Seamans JK, Yang CR (2004). The principal features and mechanisms of dopamine modulation in the prefrontal cortex. Prog Neurobiol 74: 1-58.

Seeman P (1999). Images in neuroscience. Brain development, X: pruning during development. Am J Psychiatry 156: 168.

Stefanis NC, Delespaul P, Henquet C, Bakoula C, Stefanis CN, Van Os J (2004). Early adolescent cannabis exposure and positive and negative dimensions of psychosis. Addiction 99: 1333-1341.

Stokes PR, Egerton A, Watson B, Reid A, Breen G, LingfordHughes A et al (2010). Significant decreases in frontal and temporal $[11 \mathrm{C}]$-raclopride binding after THC challenge. Neuroimage 52: 1521-1527.

Stokes PR, Egerton A, Watson B, Reid A, Lappin J, Howes OD et al (2011). History of cannabis use is not associated with alterations in striatal dopamine D2/D3 receptor availability. J Psychopharmacol 26: 144-149.

Tanda G, Pontieri FE, Di Chiara G (1997). Cannabinoid and heroin activation of mesolimbic dopamine transmission by a common mu1 opioid receptor mechanism. Science 276: 2048-2050.

Tsou K, Brown S, Sanudo-Pena MC, Mackie K, Walker JM (1998). Immunohistochemical distribution of cannabinoid CB1 receptors in the rat central nervous system. Neuroscience 83: 393-411.

Tunbridge EM, Harrison PJ, Weinberger DR (2006). Catechol-omethyltransferase, cognition, and psychosis: Val158Met and beyond. Biol Psychiatry 60: 141-151. van Os J, Bak M, Hanssen M, Bijl RV, de Graaf R, Verdoux $H$ (2002). Cannabis use and psychosis: a longitudinal populationbased study. Am J Epidemiol 156: 319-327.

van Os J, Kenis G, Rutten BP (2010). The environment and schizophrenia. Nature 468: 203-212.

Vazdarjanova A, Bunting K, Muthusamy N, Bergson C (2011). Calcyon upregulation in adolescence impairs response inhibition and working memory in adulthood. Mol Psychiatry 16: 672-684.

Verdoux H, Sorbara F, Gindre C, Swendsen JD, van Os J (2003). Cannabis use and dimensions of psychosis in a nonclinical population of female subjects. Schizophr Res 59: 77-84.

Volk D, Austin M, Pierri J, Sampson A, Lewis D (2001). GABA transporter-1 mRNA in the prefrontal cortex in schizophrenia: decreased expression in a subset of neurons. Am J Psychiatry 158: $256-265$.

Welch KA, McIntosh AM, Job DE, Whalley HC, Moorhead TW, Hall J et al (2011). The impact of substance use on brain structure in people at high risk of developing schizophrenia. Schizophr Bull 37: 1066-1076.

Wilson N, Cadet JL (2009). Comorbid mood, psychosis, and marijuana abuse disorders: a theoretical review. J Addict Dis 28: 309-319.

Yavich L, Forsberg MM, Karayiorgou M, Gogos JA, Mannisto PT (2007). Site-specific role of catechol-O-methyltransferase in dopamine overflow within prefrontal cortex and dorsal striatum. I Neurosci 27: 10196-10209.

Yucel M, Solowij N, Respondek C, Whittle S, Fornito A, Pantelis C et al (2008). Regional brain abnormalities associated with long-term heavy cannabis use. Arch Gen Psychiatry 65: 694-701.

Zammit S, Owen MJ, Evans J, Heron J, Lewis G (2011). Cannabis, COMT and psychotic experiences. Br J Psychiatry 199: 380-385. 